\title{
Research on Bilingual Teaching Mode of Communication Engineering Specialty in Nationalities Universities Based on Cultivation of Engineering Ability
}

\author{
Ting $\mathrm{Li}^{1, \mathrm{a}}$, Hong Tang ${ }^{2, \mathrm{~b}}$ \\ ${ }^{1}$ College of Information and Communication Engineering, Dalian Minzu University, Dalian Liaoning \\ 116605, China; \\ ${ }^{2}$ Faculty of Electronic Information and Electrical Engineering, Dalian University of Technology, \\ Dalian Liaoning 116033, China \\ aliting@dlnu.edu.cn, btanghong@dlut.edu.cn
}

Keywords: cultivation of engineering ability; nationalities universities; communication engineering; bilingual teaching

\begin{abstract}
In this paper, on the basis of actual situation of communication engineering specialty in the nationalities university, the reform of bilingual teaching method based on cultivation of engineering ability is carried out. The contents of English courses are enriched by engineering ability training. Bilingual teaching method of code switching is used in all the specialized courses. Bilingual teaching is also carried out in practice and project teaching, which encouraged students to write English experiment reports, English project reports, little English papers and so on. Learning English from doing, the students' interests are aroused. The bilingual teaching mode based on cultivation of engineering ability has been applied in students from Grade 2009 to 2012, and good teaching effects have been achieved.
\end{abstract}

\section{Introduction}

Communication engineering is a typical engineering specialty, which is an innovative engineering specialty to train students of designing, developing and manufacturing. Communication engineering specialty which needs strong practicality and engineering background requests students not only solid theoretical foundations but also strong abilities of engineering practical ability. At the same time, the Ministry of Education has implemented the "Excellent Engineer Education Program", the main purpose of which is to train a large number of high-quality engineering and technical professionals who can adapt to the economic and social development needs and has innovative ability. Communication technology and industry which updates very fast is one of the fastest-growing areas since 1980s. In order to increase the international competitiveness to improve the level of innovation, we must follow advanced technology in foreign countries, which makes possible to develop more independent intellectual property rights of the core technology in China. At present, in the field of communication, a lot of new knowledge and technology come from the developed countries in Europe and America, many new knowledge and technology as well as a large number of academic papers are written in English. Therefore, cultivating students' ability of using English in engineering practice is one of the main objectives of communication engineering specialty. At present, the bilingual teaching in the undergraduates is an important measure to promote the teaching reform and the quality of teaching under the new situation, which is the objective of education internationalization. So in the courses of communication engineering specialty, aiming at the cultivation of the ability for engineering, it is significant to establish the innovative features of the bilingual teaching mode to improve students' professional English and the ability of using English in engineering practice. It is good to cultivate excellent professional qualities and language communication ability of communication engineering students [1-2]. From the actual situation of Dalian Minzu University, combined with the author's own teaching experience, we take communication engineering specialty as an example to summarize and analyze the problems in cultivation of bilingual teaching process which is based on engineering capability in Nationalities 
universities. We also put forward the effective teaching methods, which really improve the students' English ability.

\section{Major Problems Faced in the Practice of Bilingual Teaching}

\subsection{Uneven English Level of Students}

As a nationalities university, the proportion of ethnic minority students is greater than $60 \%$, many of whom are from Xinjiang, Tibet and other remote areas. English foundations of these minority students are weak, even some of them learned "mute English". While some other students who are from developed areas are good at English, and their listening, speaking, reading and writing skills are relatively high. This caused the uneven level of students. How to take both into account is the main problem we have to face in the bilingual teaching.

\subsection{Less Attention to English Learning}

Communication engineering is an engineering specialty, so most of the students pay more attention to technical knowledge and the cultivation of practical ability. They have little interest in English learning, because they think English is just a tool which probably won't be used in the future. As everyone knows, a lot of excellent simulation software, advanced science and technology paper, chip data sheet and excellent textbooks are written in English. If there is no communication professional vocabulary, it is difficult to read the literatures so as to not be able to do scientific research and learning. Moreover, the working language of many multi-national corporations' is English. If you want to enter multi-national corporations, listening, speaking, reading and writing of English are the most basic skills. Therefore, how to improve students' interest in English learning, how to change "want me to learn" to "I want to learn", are the main problem we have to solve.

\subsection{Lack of Bilingual Teachers}

An excellent bilingual teaching staff is the prerequisite and guarantee for bilingual teaching. At present, many teachers of communication engineering specialty in universities only have a good command of professional courses, but they do not have the ability to teaching in English. And other problems, such as selection of bilingual courses and English textbooks, teacher-student interaction in the class and so on, are also needed to consider.

\section{Solutions}

In view of the problems above, combining the characteristics of nationalities universities, we carry out the following teaching reform. The method diagram is shown in Fig. 1.

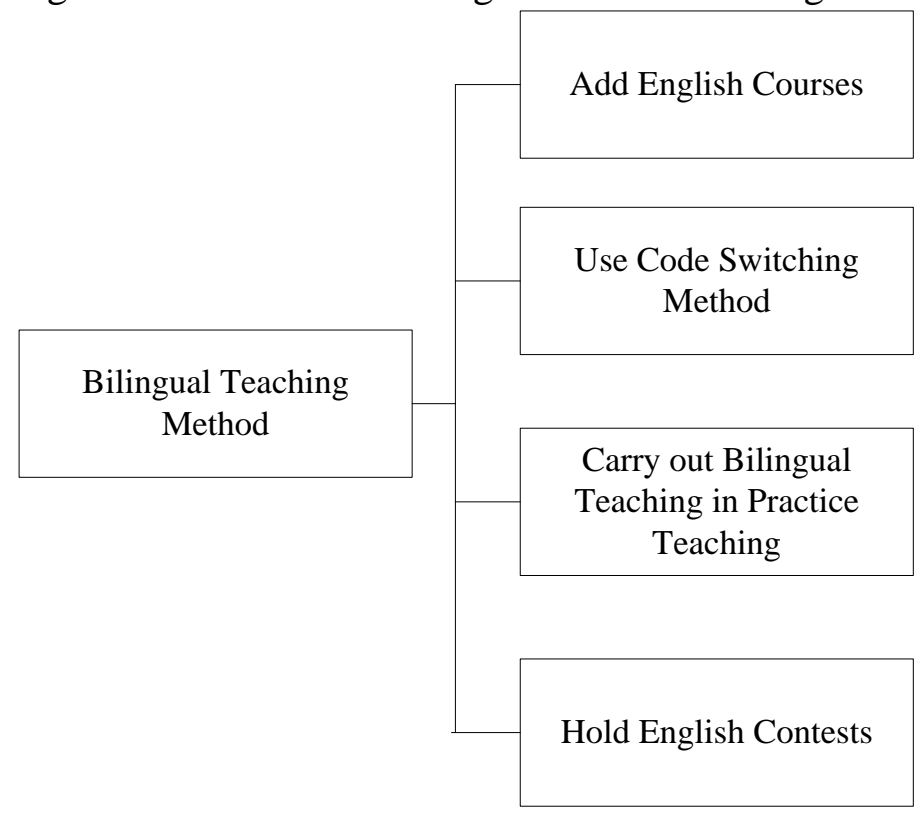

Fig. 1 The method diagram 


\subsection{Adding English Courses and Enriching the Curriculum}

In order to strengthen the students' English learning, we establish English courses of communication engineering in the fifth and sixth semesters. The course is 32 hours in each semester to increase English teaching time and the intensity of English teaching. For the cultivation of engineering ability of students in nationalities universities, we put emphasis on the reading ability of English technical standards, manuals and chip sheets [3]. After select the representative literatures from each type of English materials, we explain them to students in detail, which makes students read related literatures independently. English abstracts, papers, cover letters, resumes and other related practical writing skills are also added to meet the requirements of students to understand the advanced and practical communication technology [4-5]. In order to facilitate the students to find literatures when they do the graduation project and other practices, how to search in the online foreign literature databases to retrieve literatures and how to read English literatures are also introduced.

In the class of English for communication engineering, we establish a teaching process which treats student as the main body of the class, trying to change the situation of "the teacher speaks while students listen and the teacher writes while students copy" in the past. Teachers work as guides to explain translation and writing methods and skills mainly. Students who are the main body of the class participate in the application of these methods and skills to complete the corresponding task. First of all, in order to improve the students' spoken English and catch up with the development trend of new technology, we carry out the activity of English oral presentation. Each of the students determines issues related to communication engineering by themselves. They themselves collect information and make PPT and oral presentation the time of which is about 5 minutes in English. Secondly, in order to train the students' ability of teamwork and the ability of translation, we have conducted the activity of group translation. Teachers will download some cutting-edge and popular science and technology papers from famous journals, conferences and other databases, which are translated by every group. Students draw lots to decide the grouping, 5-6 students per group. They elect their own group leader, who is in charge of all things including distribution of translation tasks, final editing of the translation, printing and submitting. The group leader should also choose a student from the group to make an English report, introducing the content of the translation to all students. All students in the same group get the same score.

Using these methods, the students of communication engineering began to attach more importance to the English course and become more interested in it, so that the effect of learning is good.

\subsection{Use of Code Switching in Bilingual Teaching}

In nationalities universities, some students are good at English reading and writing, while some students' vocabulary is very small. In view of the students' English level gap being too large, we adopt a combining method of the bilingual teaching and code switching bilingual teaching [6-7]. For the students whose English foundations are good, we offer bilingual courses such as the circuit principle, the microcomputer principle and so on. These courses which use English teaching materials are taught entirely in English. Students who do well in English can choose these courses freely, while other students can choose the corresponding Chinese courses. To enlarge the students' vocabulary, we use code switching bilingual teaching method in all specialized courses [8-9]. In each class, 3-5 English words related to this lesson are showed and explained. Thus, in the context, the students remember these words faster and more firmly. Moreover, learning English in specialized courses, students are more likely to be interested in teaching, and it received a good teaching effect. This kind of code switching bilingual teaching method is more suitable to minority students whose English foundations are weak, and the requirements for teachers' English proficiency are not high, which is easy to perform. In addition, we have also written a code switching bilingual teaching materials (already published by Press of Dalian University of Technology), which includes English vocabulary of all specialized courses. All words are both in English and Chinese, which can be used as materials for bilingual teaching in the class and can also be used as a reference book. In this book, we also 
carefully prepared the content of how to write the experiment reports, abstracts and papers in English, accompanied by examples, to help students improve their English writing level.

\subsection{Carry out Bilingual Teaching in Practice Teaching}

For the students of communication engineering in nationalities universities, it is an important goal to improve the practical ability of students. In order to cultivate engineering talents, we set many experiments, curriculum designs, and practices in the teaching procedures. We also set up studios in which students can do research with teachers' guide. A lot of innovation contests of college and university level are organized to let students show their achievements. In these practical teaching procedures, we also actively carry out bilingual teaching. In the experimental class, we encourage students who learn English well to write experiment reports in English. They can write only one or several experimental reports in English, and the rest of them in Chinese, or all the experimental reports are written in English. Students who write English experimental reports can get extra points to enhance their enthusiasm. In the courses of design and practice, students usually design a product to achieve a certain function. We encourage students to write product specification or practice summary report in English. Also, students who write in English can get extra points. In the studio, each teacher can guide 5-6 students who complete different tasks. In every studio, we regularly carry out seminar every month to report and communicate with other students and teachers. The students make PPT and oral presentation in English, introducing their own research contents and progresses to the teachers and students. This activity has gained good results. When foreign experts and scholars visited the studio, our students can introduce studio status and their work with relatively fluent English, and can exchange academic information with foreign experts and scholars.

\subsection{Hold English Contests Actively}

Students are encouraged to write English papers, English experimental reports and translate English science and technology papers into Chinese in a variety of theoretical courses, experiment courses and practical projects. They can not only get extra and high points in the courses, but also participate in the contests organized by the university. Every year out university holds contests of English papers, English experimental reports and scientific literature translations. The prizes are decided by the quality and quantity of the works. The winner will receive a certificate and get extra point in the scholarship competition. The winning English essays and scientific literature translations will be organized and published in the university at last. In the process of graduated student and job interviews, these published papers can verify the students' English level, which plays a positive role in the interview.

\section{Conclusions}

We developed the bilingual teaching reform based on cultivation of engineering ability in Communication Engineering Specialty, College of Information and Communication Engineering, Dalian Minzu University, including increasing time of English courses of communication engineering, using code switching bilingual teaching method, and intensifying the bilingual teaching in practice projects. The reform was carried out in students in Grade 2009, 2010, 2011 and 2012, a total of 16 classes, and the results were summarized and investigated preliminarily. Most of the students' learning interests and enthusiasms were increased, knowledge extended, and English level improved. Most of the students thought the results of bilingual teaching played a certain role in the graduated student and job interviews.

To promote bilingual teaching in universities is the need to cultivate excellent talents with international competitiveness. Bilingual teaching not only instructs students English or technology, but also makes them cognize professional technology in English, that is to cultivate the ability to receive the latest communication techniques, so that students will keep track of the development of frontier in the future work. We will continue to work hard to improve teaching methods and means to improve the English level of minority students, contributing to the international development of ethnic minority areas. 


\section{Acknowledgment}

This work is supported by Characteristic Specialty of Dalian Minzu University.

\section{References}

[1]. Zhang Lian, Liu Wei, Hu Xiaoqian. The research and practice of bilingual teaching of electrical engineering foundation based on engineering ability. Journal of Chongqing Electric Power College, 2014, 19 (3): 9-12. (in Chinese)

[2]. Li Xiang, He Donggang, Li Xinxin, Li Chunhong. The theory and practice of bilingual teaching in the field of telecommunications. Teaching System Research Higher Education, 2015, 5: 3-5. (in Chinese)

[3]. Ma Yanlong, Liao Yi. Teaching exploration of university bilingual curriculum "doing by learning, learning by doing". Science and Technology Innovation Herald, 2014, 36: 219-220. (in Chinese)

[4]. Li Xiaomei, Liu Yubin, Liu Zhentian. An analysis of the quality control and evaluation system of bilingual teaching of code switching: a case study of Dalian Nationalities University as an example [J]. Heilongjiang Higher Education Research, 2013, 8: 174-178. (in Chinese)

[5]. Li Xiaomei, Du Yuanhu, Liu Yubin, Bai Rixia, Cai Mingde. Investigation and analysis of five bilingual teaching cases of code switching [J]. Nationalities Education Research, 2012, 5:95-101.

[6]. Yang Ling, Cheng Yun, Liu Jianmin. Discussion on the reform of bilingual teaching in the major of communication engineering [J]. Computer Teaching and Education Informatization, 2009, 5 (12): 3179-3180. (in Chinese)

[7]. Hu Haoran, adorable. Bilingual teaching of professional communication engineering [J]. Science and Technology Studies, 2012, 4: 41-42. (in Chinese)

[8]. Luo Chan, Ma Munakata. Reform of English classroom teaching on the teaching of Communication Engineering. Education Forum [J], 2010, 24: 12-13. (in Chinese)

[9]. Wu Zhimin, Dai Lingli. Research and discussion on English teaching and learning in communication engineering [J]. China Educational Technology and Equipment, 2009, 30: 34-35. (in Chinese) 